\title{
Immediate treatment of botulinum toxin type A-induced brow ptosis with polydioxanone cog thread insertion
}

\author{
Kyoung-Jin Kang, MD, $\mathrm{PhD}^{1}$, Choong-Yee Chai, $\mathrm{MS}^{2}$ \\ ${ }^{1}$ Seoul Cosmetic Surgery Clinic, Busan, Rep. of Korea, ${ }^{2}$ Korean College of Cosmetic Surgery, Busan, Rep. of Korea
}

Background: Botulinum toxin is most commonly used as a safe cosmetic injectable to improve dynamic wrinkles. However, side effects still occur. Among them, brow ptosis is known to occur relatively infrequently. The condition is self-limiting; however, for about 3 months post-injection, the patient must endure related uncomfortable symptoms. Several methods have been recommended to prevent this complication; however, no treatment has been developed to improve such symptoms instantly. Currently, various processed threads, such as polydioxanone (PDO), are widely used for facial rejuvenation; PDO thread is bio-absorbable.

Objective: The authors performed brow lifting using a cogged PDO thread to improve uncomfortable symptoms associated with brow ptosis.

Methods: In total, 14 PDO threads with multi-bidirectional cogs (two 1.0 threads, with lengths of $9.0 \mathrm{~cm}$ each, and twelve 1.0 threads, with lengths of $6.0 \mathrm{~cm}$ each) were placed in 7 rows, which were inserted into the superficial fat layer and deep fat layer (dual plan insertion) separately, at approximately $1.0-\mathrm{cm}$ intervals.

Results: Following the use of the thread, the positions of the left and right eyebrows were observed to have slightly increased by an average of $1.43 \pm 0.65 \mathrm{~mm}$ and $1.7 \pm 0.9 \mathrm{~mm}$ after two weeks, respectively; the patients indicated a high degree of satisfaction with immediate improvement of the uncomfortable symptoms.

Conclusion: It is suggested that PDO thread brow lifting would be a reliable procedure to immediately treat botulonum-toxin induced brow ptisos noninvasively.

Keywords: botulinum toxin; brow ptosis; polydioxanone thread; forehead wrinkle

\section{Introduction}

Botulinum toxin is a safe and commonly used cosmetic injectable. However, upper facial botulinum toxin injection can lead to relatively mild side effects, such as pain, hematoma, ecchymosis, bruising, lid and brow ptosis, and eye sensory disorders [1].

Eyebrow ptosis occurs infrequently but typically develops when botulinum toxin is injected to improve transverse forehead wrinkles. It is manifested by persistent swelling, transverse nasal dorsum wrinkles, lowered brow position, and upper lid crease narrowing and is accompanied by other symptoms, such as feelings of heaviness and headache. The incidence and severity of some of these symptoms are somewhat different among studies, although some of them are anecdotal $[2,3]$. Most physicians think that these symptoms are minor because they are temporary and self-limited to within 3 months following injection [3]. However, there is currently no appropriate treatment that can instantly improve these symptoms.

In this case series, we performed brow lifting using cogged 
polydioxanone (PDO) thread [4] to improve brow ptosis, including associated uncomfortable symptoms, in several patients. PDO thread has already been used in the human body as absorbable sutures for sternal closure during open cardiac surgery; however, it has been actively used recently as a facial tightening and lifting method in Korea [5,6]. It is safe and effective and is associated with only minor complications when performed on patients with modest face sagging, fine wrinkles, and/or marked facial pores. The incidence of these complications is low and not serious [6].

Therefore, with the results of four interesting cases in which brow ptosis and accompanying uncomfortable symptoms were instantly improved using PDO thread, the authors propose the possibility of a new treatment method to improve the abovementioned side effects.

\section{Materials and methods}

\section{Patients and botulinum toxin}

Four women in their 50s and 60s, who developed brow ptosis after receiving botulinum toxin (Meditoxin ${ }^{\circledR}$; Medytox Inc., Seoul, Republic of Korea) to improve upper facial wrinkles, were followed up for 2 weeks to 3 months after PDO brow lifting.

\section{PDO thread}

The PDO thread (Anti-Aging Sequential Thread Insertion, $\mathrm{ASTI}^{\circledR}$ forehead\&temple Kit; Mediwire Co. Ltd., Daegu, Republic of Korea) used for brow lifting is shown in Fig. 1.

\section{Anesthesia}

A $2 \%$ lidocaine solution was used for sensory block in the supratrochlear and supraorbital nerves, and the skin entry sites were desensitized using $1 \%$ lidocaine with epinephrine $(1: 100,000)$.

\section{Double-Layer PDO thread insertion}

Two 1.0 cogged PDO threads $(9.0 \mathrm{~cm}, 2$ rows; $6.0 \mathrm{~cm}, 12$ rows $)$ with different lengths were inserted in dual layers at $-1.0-\mathrm{cm}$ intervals (Fig. 2). The thread was inserted into the supraperios- teal layer in the upper half of the forehead and into the galeal fat pad and brow fat (i.e., the deep layer approach) in the lower half of the forehead. Next, a new thread was inserted into the subcutaneous superficial fat layer through the same entry site (i.e., the superficial layer approach). 3M tape was used to fix the forehead for 3 days post-procedure, and cold compression was applied for 2 days.

\section{Brow position measurement}

Brow shape and position changes were observed using preand post-operative photographs. The distance between the vertical descending line from the superomedial eyebrow angle and horizontal connecting line between the medial canthi was measured to assess the eyebrow position changes (Fig. 2a, b, and c).

\section{Patient subjective satisfaction grading survey}

A simple patient satisfaction survey was conducted on each patient 2 weeks after the procedure. The satisfaction degree on six brow morphological change items and three uncomfortable

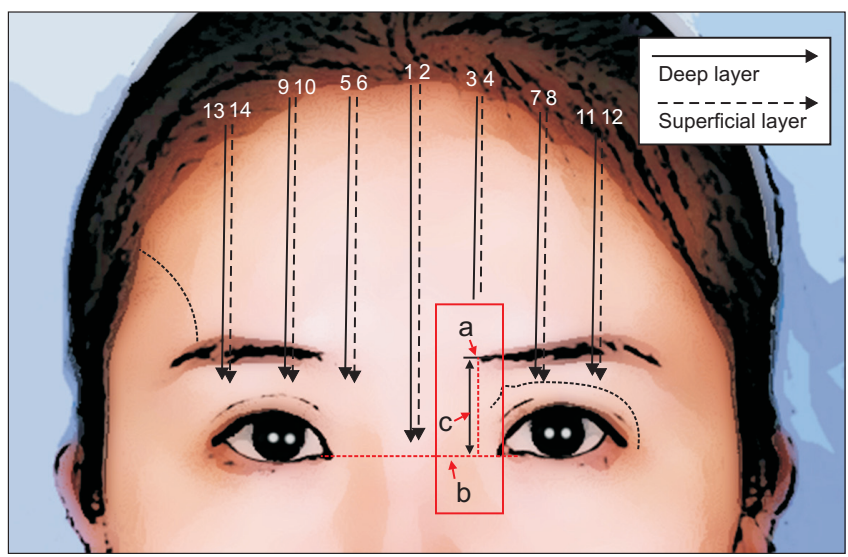

Fig. 2. Double-layer sequential insertion of multi-directional cogged PDO thread. The numbers (i.e., 1 to 12) represent the insertion of the thread in order. Numbers 1 and 2 are 9 -cm-long threads, and the others are 6-cm-long threads. Morphometric measurement of the brow position (red square): a, superomedial angle of the eyebrow; $b$, connecting line between both medial canthi; $c$, distance between a and $b$.

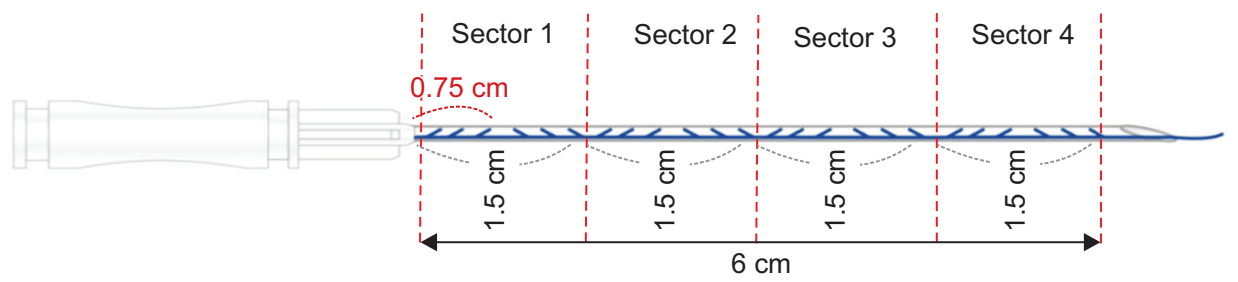

Fig. 1. 1.0 PDO thread with multi-bidirectional cogs. The 1.0 PDO thread consists of $4(60 \mathrm{~mm})$ or $6(90 \mathrm{~mm})$ sectors of $\operatorname{cog}$ (bidirectional cog length per sector, 1.5 $\mathrm{cm})$, which is inserted into a 23-gauge needle. 
Table 1. Patients' subjective satisfaction grades

\begin{tabular}{|c|c|c|c|c|c|c|c|c|c|c|c|}
\hline & \multicolumn{7}{|c|}{ Satisfaction grades to brow morphological change } & \multicolumn{4}{|c|}{ Satisfaction grades to uncomfortable symptoms } \\
\hline & $\begin{array}{c}\text { Transverse } \\
\text { wrinkles }\end{array}$ & Swelling & Sagging & $\begin{array}{c}\text { Asymmetric } \\
\text { brow }\end{array}$ & $\begin{array}{c}\text { Upper } \\
\text { eyelid } \\
\text { skin laxity }\end{array}$ & $\begin{array}{c}\text { Forehead } \\
\text { depression }\end{array}$ & $\begin{array}{c}\text { Average } \\
\pm \text { SD }\end{array}$ & Heaviness & Headache & $\begin{array}{c}\text { Difficult } \\
\text { upper } \\
\text { lid opening }\end{array}$ & $\begin{array}{c}\text { Average } \\
\pm S D\end{array}$ \\
\hline Case 1 & 3 & 3 & 4 & 4 & 2 & 3 & $3.17 \pm 0.75$ & 5 & 5 & 4 & $4.67 \pm 0.58$ \\
\hline Case 2 & 4 & 3 & 4 & 3 & 2 & 2 & $2.83 \pm 0.75$ & 5 & 5 & 4 & $4.67 \pm 0.58$ \\
\hline Case 3 & 2 & 1 & 2 & 2 & 2 & 3 & $2.00 \pm 1.63$ & 4 & 4 & 4 & $4.00 \pm 0.00$ \\
\hline Case 4 & 5 & 3 & 5 & 5 & 5 & 2 & $4.17 \pm 1.33$ & 4 & 5 & 5 & $4.33 \pm 0.58$ \\
\hline $\begin{array}{c}\text { Average } \\
\pm \mathrm{SD}\end{array}$ & $3.5 \pm 1.30$ & $2.5 \pm 1.00$ & $3.75 \pm 1.26$ & $3.5 \pm 1.29$ & $2.75 \pm 1.50$ & $2.5 \pm 0.58$ & $3.08 \pm 1.17$ & $4.5 \pm 0.58$ & $4.75 \pm 0.5$ & $4.25 \pm 0.5$ & $4.45 \pm 0.52$ \\
\hline
\end{tabular}

Consensus ratings from the patients themselves were evaluated at two weeks after the procedure. Subjective outcomes were divided among "exceptional=5", "excellent=4", "good=3", “fair=2", "poor=1", and "very poor=0".

symptom items was graded (Table 1).

\section{Results}

The brows that exhibited an angry appearance changed to those exhibiting a bright appearance; the sagging phenomenon above the glabella improved $\left(a \rightarrow a^{\prime} \rightarrow a^{\prime \prime}\right)$; and soft tissue sagging in the nasion and glabella $\left(b \rightarrow b^{\prime} \rightarrow b^{\prime \prime}\right)$ and transverse wrinkles $\left(c \rightarrow c^{\prime} \rightarrow c^{\prime \prime}\right)$ improved remarkably (Fig. 3).

Following the procedure, the left and right eyebrow positions increased by an average of $1.43 \pm 0.65 \mathrm{~mm}$ and $1.70 \pm 0.90 \mathrm{~mm}$ after 2 weeks and $0.4 \pm 0.27 \mathrm{~mm}$ and $0.75 \pm 0.61 \mathrm{~mm}$ after 3 months, respectively. The pre- and post-operative ratios of the superior angle position of the medial brow increased; specifically, the left and right brows increased to $106.6 \pm 3.15 \%$ and $107.8 \pm 4.70 \%$ after 2 weeks and decreased to $101.8 \pm 1.24 \%$ and $103.4 \pm 3.00 \%$ after 3 months, respectively (Fig. 3 and Table 2).

The brow ptosis symptoms improved immediately after the procedure, which lasted up to 3 months. The average morphological side effect-related improvement satisfaction was 3.08 \pm 1.17 (Grade 3: good), and the functional side effect-related improvement satisfaction was $4.45 \pm 0.52$ (Grade 4: excellent) (Tables 1, 2, and Fig. 3).

\section{Discussion}

The majority of botulinum toxin-induced side effects have been reduced significantly because of cosmetic surgery developments, such as better anatomical knowledge, more careful injection methods, and injections combined with other cosmetic procedures [2]. Unfortunately, no immediate and direct treatment for complications has been reported yet; methods that prevent these side effects are reported. Currently, the only immediate therapeutic option for these side effects is surgical brow lift.

The PDO thread diameter in the tissues decreased by $12.5 \%$ (3 months) and $87.5 \%$ (6 months), and most patients (87\%) who underwent PDO thread lifting were considerably satisfied with their outcomes even after 24 months post-operatively [7].

In this study, the brow position change was measured on the basis of the photographs taken after the PDO thread brow lifting and patient satisfaction survey completion. The brow position change was measured at the superomedial brow angle because that is where the greatest brow position changes in brow ptosis and side effect-associated symptoms occur.

In all cases in this study, brow ptosis occurred severely at the inner half of the brows. After the brow lifting procedure, the eyebrows trended more towards the natural eyebrow shape owing to the rise at the inner half of the eyebrows. Improvement of sagging with new transverse wrinkle formation in the middle lower forehead and decreased volume in the nasal dorsum with nasal transverse wrinkle softening were observed as obvious evidence of eyebrow lifting (Fig. 3).

Iblher et al. reported that measurements taken from the inner one-third of the brows 3 months after endoscopic brow lifting showed eyebrow lifting rates of $110 \%-115 \%$ [8]. Although the measurement positions were slightly different, the brow lifting rates were $100 \%-108 \%$ in our study (Table 2). Our results are significant, although the lifting effect is lesser than that of endoscopic brow lifting because our primary goal was uncomfortable symptom improvement using a non-invasive procedure.

In addition, the brow lifting rate over 2 weeks to 3 months after the procedure (Table 2 and Fig. 3) decreased. The pre- and post-operative ratio (\%) decrease at 2 weeks and 3 months (Table 2) corresponded to the results by Molea et al. The PDO thread tissue changes were determined to be decreases in the inflammatory reaction diameter, inflammatory cell density, and PDO thread diameter [9]. 


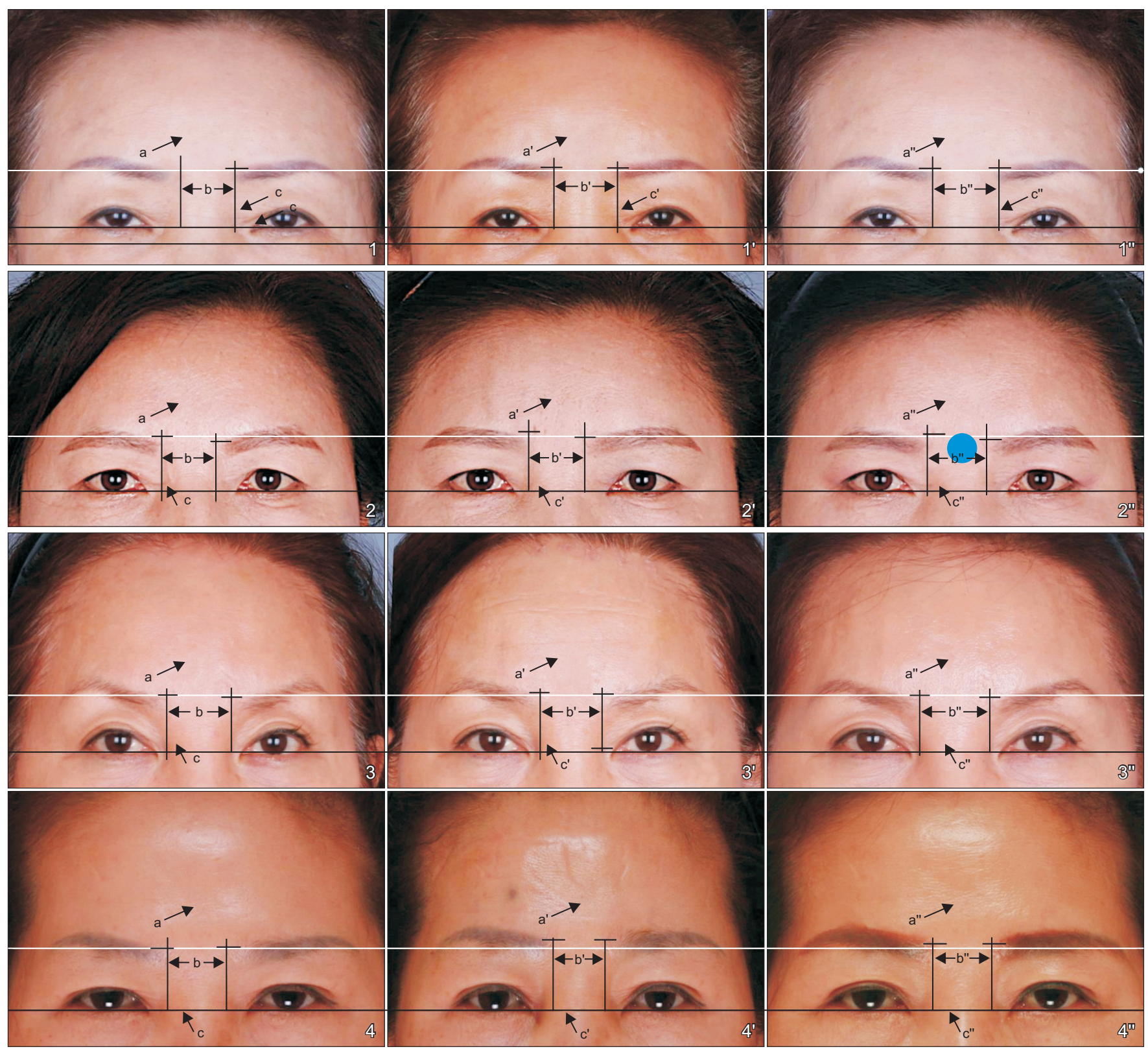

Fig. 3. Morphological changes of the ptotic brows and their surrounding soft tissues by brow lifting using cogged PDO threads. Four women $(1,2,3$, and 4) underwent botulinum toxin injection for improvement of the forehead, glabella or/and crow's feet. Side effects happened twoto-three days after the procedure. Three-to-seven days after the botulinum toxin injection, all three patients received brow lifting using PDO threads. The patients were followed up for two weeks (1',2',3', and 4') to a maximum of three months (1", 2", 3", and 4") after the brow lifting procedure. a-a", forehead volume deficiency; b-b", swelling and sagging of glabella, nasion, and upper eye lid; and c-c", transverse wrinkle.

In the study by Bulstrode and Grobbelaar, botulinum toxininduced brow ptosis varied from 1 to $6 \mathrm{~mm}$ (mean, $2.3 \mathrm{~mm}$ ) [10]. In our study, brow lifting using PDO threads averaged to $1.56 \mathrm{~mm} 2$ weeks post-operation; although it was difficult to compare the mean values because there was no pre-operative measurement, it can still be regarded as a meaningful result based on the above-mentioned brow lifting rate. Although PDO thread brow lifting could not completely improve brow ptosis morphologically, and despite the post-operative swelling, the other uncomfortable symptoms, such as headache and heaviness with eyelid opening difficulties, disappeared almost immediately after the procedure and did not recur until 3 months post-procedure. All the patients showed a higher satisfaction degree with regards to uncomfortable symptom improvements compared with morphological improvements based on the satisfaction survey (performed 2 weeks post-operatively) when 
Table 2. Effects of PDO brow lifting on the botulinum toxin-induced brow ptosis

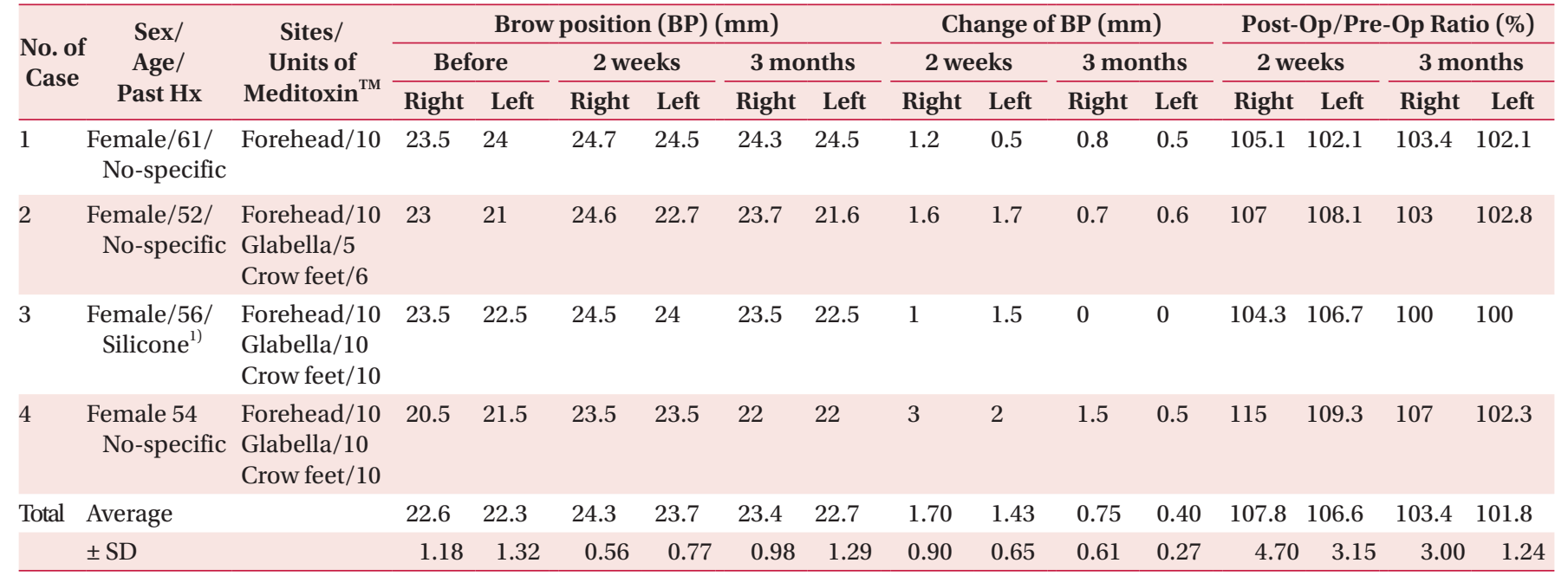

${ }^{1)}$ Note: the patient in case 3 had undergone a silicone injection into the glabella area 20 years prior.

post-operative swelling had mostly disappeared (Table 1).

Case 3 had the lowest satisfaction in terms of uncomfortable symptom relief because of the continuous swelling caused by the inflammation reaction of the previous silicone injection into the glabella. Nevertheless, her satisfaction with the uncomfortable symptom improvement was high, although she had the lowest morphological improvement.

In addition, the overall uncomfortable symptom improvement had higher associated satisfaction grades than the morphological improvement. Immediate uncomfortable symptom improvement then yields higher satisfactions to patients with significant discomfort and anxiety (i.e., worry about complete recovery) due to the side effects.

Although this study showed significant brow lifting effects, and considering that PDO brow lifting application should be further examined owing to the small case number, the application of this procedure as a method to improve botulinum toxininduced brow ptosis is considered significant, as it is the first time such a non-invasive method was proposed.

The analysis of more cases with longer follow-up periods and brow position measurement prior to botulinum toxin injection are warranted to confirm PDO thread usage in brow lifting for brow ptosis improvement. Morphologic change data at 3 and 6 months after PDO brow lifting are needed as further clinical evidence.

\section{Conclusion}

Performing a simple non-invasive PDO thread brow lifting is worthy as it effectively improves botulinum toxin-induced brow ptosis and reduces the accompanying side effects.

\section{Conflicts of interest}

The authors have nothing to disclose.

\section{References}

1. Wollina U, Konrad H. Managing adverse events associated with botulinum toxin type A: a focus on cosmetic procedures. Am J Clin Dermatol 2005;6:141-50.

2. Ascher B, Rossi B. [Botulinum toxin and wrinkles: few side effects and effective combining procedures with other treatments]. Ann Chir Plast Esthet 2004;49:537-52. French.

3. Klein AW. Complications and adverse reactions with the use of botulinum toxin. Dis Mon 2002;48:336-56.

4. Jang HJ, Lee WS, Hwang K, Park JH, Kim DJ. Effect of cog threads under rat skin. Dermatol Surg 2005;31:1639-43; discussion 1644.

5. Kim J, Zheng Z, Kim H, Nam KA, Chung KY. Investigation on the cutaneous change induced by face-lifting monodirectional barbed polydioxanone thread. Dermatol Surg 2017;43:7480.

6. Suh DH, Jang HW, Lee SJ, Lee WS, Ryu HJ. Outcomes of polydioxanone knotless thread lifting for facial rejuvenation. Dermatol Surg 2015;41:720-5.

7. Kurita M, Matsumoto D, Kato H, Araki J, Higashino T, Fujino $\mathrm{T}$, et al. Tissue reactions to cog structure and pure gold in lifting threads: a histological study in rats. Aesthet Surg J 2011;31:347-51. 
8. Iblher N, Manegold S, Porzelius C, Stark GB. Morphometric long-term evaluation and comparison of brow position and shape after endoscopic forehead lift and transpalpebral browpexy. Plast Reconstr Surg 2012;130:830e-40e.

9. Molea G, Schonauer F, Bifulco G, D’Angelo D. Comparative study on biocompatibility and absorption times of three absorbable monofilament suture materials (Polydioxanone, Poliglecaprone 25, Glycomer 631). Br J Plast Surg 2000;53:13741.

10. Bulstrode NW, Grobbelaar AO. Long-term prospective followup of botulinum toxin treatment for facial rhytides. Aesthetic Plast Surg 2002;26:356-9. 